\title{
Research on Integrity Education of Graduates' Employment in Agricultural Colleges and Universities
}

\author{
Chao Wang ${ }^{1, ~ a}$ and Junzheng Wang ${ }^{1, b^{*}}$ \\ ${ }^{1}$ Xincheng Street 2888, Jilin Agricultural University, Changchun, Jilin Province 130118, PR China \\ a29251275@qq.com, b595845966 @ qq.com \\ ${ }^{*}$ The Corresponding author
}

Keywords: Colleges and Universities; Graduates; Employment; Integrity education

\begin{abstract}
Recently, the Ministry of Education has issued a revised "Regulations on the Management of Students in Ordinary Colleges and Universities". The provisions clearly pointed out that in colleges and universities to carry out integrity education, the establishment of the act of restraint and disciplinary mechanism. Honesty is a person in the social survival of the basic moral requirements, but in real life, there are still some students there is such a or that dishonesty. This paper analyzes the current integrity problems of college graduates, puts forward the corresponding measures to achieve the purpose of improving the overall integrity of graduates, and then cultivate the socialist core values of college students.

Carrying out the honesty education of college students is a vital content of the current ideological and political education in colleges and universities. Carrying out the honesty and education of college students is concerned with the development of college students' outlook on life, values and world outlook. The Ministry of Education has once again clear the importance of integrity education. In recent years, with the expansion of colleges and universities and widening out of the strict education model, leading to the current employment situation and pressure of college students increasingly severe. In this situation, college students tend to "take the risk", through some disgraceful behavior to achieve their purpose of employment. Therefore, the current colleges and universities need to strengthen the integrity of education and system construction, through a series of graduates integrity education activities, so that students with integrity awareness, sense of responsibility, and then for the community to cultivate and output honest and trustworthy graduates.
\end{abstract}

\section{The Current College Graduates Lack of Integrity of the Specific Performance}

Employment Resume There Is False Information. Employment resume there are false information is mainly reflected in two aspects: First, the graduates recommend that there are false information table. Graduates employment recommendation table is the current university to the employer to recommend their students to choose their own materials, a written material. The recommendation table contains information about students' personal information, grades, scholarships, social practice, and so on. Graduates recommended table can be a good reflection of the performance of graduates during the school. However, in practice, due to the large number of students each grade, counselors can not personally fill each student's situation, can only be a detailed guide to how graduates fill out and precautions. When the author personally verified graduates fill out the information, it can be said to be "varied", there are forged social practice experience, there are forged CET-4 or CET-6, there are forged student cadres experience, there are forged computer grade examination. Second, there is false information on job resume. Zhengzhou City Talent Exchange Center has been investigated more than 500 enterprises and institutions in the employment of college graduates conducted a survey of integrity in 2011, the results show that $28 \%$ of the recommended materials and the real situation does not match. ${ }^{[1]}$ Job resume as a graduate writer to write a job information, with independent, open features, counselors often do not deliberately check the authenticity of graduates resume, which is likely to cause graduates resume resume information The consequences of flooding. There is no regulation, no constraints, graduates in the production of job resume changed more arbitrary, very good at his face paste gold, which 
usually led to a lot of squad leader, party secretary, student cadres chaos.

Unilateral Breach of Contract Is Common. At present, graduates have a rigid phenomenon, that is, graduates in the employment of double election and job fairs, will be everywhere to vote resume, extensive netting, there may be a number of employers interested in hiring, the final graduates may not choose one of them. Or, graduates first looking for a relatively reliable company, signed a tripartite agreement, to be late after a better company, will be interested in default with the previous company. Or, some graduates will frequently quit, to the company before the report, the psychological job to do the correct job. According to the McCarthy Institute published the "Employment Blue Book: 2016 Chinese college students employment report" shows that the 2015 college graduates in the six months of graduation turnover rate of $34 \%$. Among them, the undergraduate and vocational colleges turnover rate was $24 \%, 43 \%$.

Water Doped During the Interview. Interview is an important method and touchstone for college graduates to employ college graduates. Through the scientific interview method, the employer can pick out the graduates with high professional accomplishment and high quotient in a short time. However, in practice, some graduates in order to obtain the unit of employment, often for some of the requirements of the employer to deliberately exaggerate their own advantages and levels. Sometimes, in the interview process, lip service, free compilation of social practice experience and work experience, in order to obtain the interviewer's approval. However, this part of the integrity of the graduates after entering the unit, which often can not really competent professional and strong work.

\section{The Reasons for the Lack of Integrity of Graduates}

Graduates Employment Pressure is Increasing. In recent years, the number of college graduates in China has been increasing year by year. Premier Li Keqiang in this year's government work report clearly pointed out: 795 million graduates of higher education this year, another record high. Coupled with the past, the employment of college graduates, graduate employment situation is still relatively grim. In the face of employment pressure, to encourage some graduates to sacrifice integrity to get valuable job opportunities.

The Weakening of Honesty Education in Colleges and Universities. For a period of time, colleges and universities in the process of carrying out ideological and political education and "two courses", the focus of education is often on the ideological and ideological development of college students, ideology, ignoring the integrity of college students education. In the current context, the lack of effective, students loved the integrity of education methods. At the same time, the school for the establishment of the mechanism and approach to dishonesty, which caused the loss of dishonesty of the university to reduce the cost of dishonesty.

The Impact of Social Macroeconomic Environment. At present, the grim employment situation forcing some college students had to take risks. Of course, some of the employer's misconduct, but also lead to the employment of graduates is an important reason for dishonesty. Part of the employing units often set some high with the requirements, free to improve the entry requirements and threshold, and then there is a high talent consumption of the phenomenon, some employers actually provide the post, often graduates of higher vocational colleges can be competent, But in order to improve the unit's "value", often require undergraduate graduates. For example, some employers to improve jobs, do not need to use English, but employers often require the need to meet the level of English four or six. At the same time, the current social credit system construction is not perfect, social credit system construction has yet to be further improved. These objective factors are also an important reason for the lack of integrity in the process of reemployment.

College Graduaduates Have Weak Self-discipline. At present, the fundamental reason for the lack of honesty and credit of college graduates lies in the weak self-discipline and weak self-discipline. This is mainly reflected in the following two aspects: on the one hand, the current environment, the value orientation of graduates and the concept of good faith there is a certain 
deviation. At present, the lack of integrity brought about by the cost of small, not too perfect failure to punish the mechanism, graduates are often too concerned about the dishonesty of some bad consequences. On the other hand, part of the overall quality of the poor graduates, in order to be able to get an ideal job, had to take risks to make some dishonesty, which led to part of the students will be the most drastic, let go of the psychological.

\section{To Strengthen the Integrity of College Graduates Employment Measures and Measures}

It is a major project and classroom to strengthen the employment honesty education of graduates of colleges and universities, and it is a major project and classroom. It needs the relevant departments of the government, society, colleges and universities and families to cooperate with each other to form a concerted effort to improve the graduates of colleges and universities The level of integrity. This requires both graduates to do moral self-discipline, integrity and self-discipline, but also the relevant departments to develop laws and regulations effective constraints.

Improve the Employment System of College Graduates Employment System. Integrity employment, integrity recruitment and integrity of the atmosphere and so need to have an external scale to control and measure, and now has a mature credit system developed countries, we can say that China's credit system is also very unsafe ${ }^{[2]}$, these objective factors Leading to a certain degree of social integrity crisis. At present, the most urgent is to improve the credit legislation and credit system construction. The relevant departments of the government should bring credit legislation and system construction into the agenda as soon as possible. Establish and improve the relevant laws and regulations, and earnestly social credit activities have laws to follow, there must be law; the relevant departments to be illegal, law enforcement must be strict degree. Education departments and colleges and universities should establish a credit management system for graduates in a timely manner. We should establish a credit system construction from primary school entrance to university graduation, covering the integrity record of graduates, integrity files and dishonesty. We should focus on strengthening the supervision of public opinion, establish the credit file system of college students, establish the credit evaluation mechanism of graduates, and establish the sharing platform of credit information of graduates. ${ }^{[3]}$

To Establish a Sound and Practicable Reward and Punishment Mechanism. To establish a perfect reward and punishment mechanism has come to the imminent moment. The mechanism of dishonesty is to regulate the integrity of citizens behavior, when the citizens travel out of faith or lead to the consequences of dishonesty, for the messenger to make a follow-up system. Reward mechanism is to encourage the majority of citizens to carry forward the positive energy, honest and law-abiding loyal practitioners, is to reward citizens in the process of building integrity and make a good deeds of a behavior. The establishment of government regulators, all kinds of credit institutions, employers and public institutions to participate in the market anti-security mechanism, the enterprises and individuals in accordance with the law according to the credit publicity, reduce the credit rating, warning tips, limit market access, limit consumption Punishment and other disciplinary. ${ }^{[4]}$ At the school level, but also the corresponding establishment of supporting mechanisms and systems, colleges and universities should be the integrity of college students through education, the integrity of college students as a daily work grasp, integrity education into the "two courses" teaching To go, so that college students always think of integrity, good practice integrity system. For those who do not keep the integrity of the rules of the students, to keep track of education and guidance in a timely manner to correct and deal with, punishment and punishment is not the purpose of education students themselves honest and trustworthy is the fundamental purpose.

To Strengthen the Integrity of Education Practice. Practice is the only standard to test the truth, we should pay full attention to the practicality of integrity education, and do a good job of learning to do a unified, learn to do a combination of theory and practice to achieve good results. People only through their own personal practice, can really the integrity of education-related theory into their own ideas and actions. As a college ideological and political education workers, to fully 
grasp and apply this law, to guide students to master the correct world view and methodology. In the means and methods of education, we should pay attention to the practice of students, to guide students to establish a correct concept of integrity, to integrate into society. To guide students in the process of participation in social activities, to be honest as the first meaning of human life. Guide students in practice to temper their own integrity and moral quality.

Vigorously Create a Good Social Environment and Atmosphere. To solve the problem of lack of integrity of graduates in the process of employment, a very important way is to guide the whole society to form a trustworthy person, everyone stresses the atmosphere of honesty, with a sound and reasonable credit mechanism to restrain and restrict the behavior of. At present, in the whole society to cultivate a good atmosphere of honesty and trustworthiness, a wide range of integrity education and publicity, vigorously cultivate and practice the socialist core values. With excellent moral fashion, to guide the improvement of the social atmosphere, and then subtle influence to develop graduates to develop good moral integrity.

Innovation Activities Carrier, to Enhance the Credibility of the Education Rate of Education. Wonderful campus cultural activities, for college students have a very strong influence and appeal, the campus cultural activities as a "two lessons" a supplementary means of education, to guide students to establish a good moral integrity, with good results. At present, colleges and universities to innovate the carrier, to attract more students to participate in the activities of integrity education, so that students grow up in the activities, learning in the activities. Fully carry out the practice of honesty and education, you can regularly carry out the integrity of the theme class, speech, debate, as the regiment activities and other students loved the activities to enhance the credibility of the audience rate of education.

\section{Acknowledgements}

This article is the Ministry of Education of Jilin Province, "thirteen five" social science research project: higher agricultural graduates employment integrity education research (project number: Jilin Educational, Scientific and Cultural Organization [2017] JJKH20170337JY) one of the results.

\section{References}

[1] Duan Weiwei.Study on Integrity Education of Contemporary College Graduates' Employment [J]. Theoretical Exploration 2012 22, 12-15

[2] Liu Zhijun. Review of university graduates' dishonesty in employment [J]. Journal of Guizhou Institute for Nationalities (PHILOSOPHY AND SOCIAL SCIENCE EDITION), 2013, (4)

[3] Chen Mingbin. University graduate employment lack of integrity analysis of the status quo [J]. School Party building and ideological education, the total 505, 16-17

[4] Shen Xia. Credit system construction and application for the Xinjiang economy and financial coordination and steady development of services survey and thinking [J]. Credit, 2013, (6) 